\title{
Application of Microbial Biopolymers as an Alternative Construction Binder for Earth Buildings in Underdeveloped Countries
}

\author{
Ilhan Chang, ${ }^{1}$ Minkyung Jeon, ${ }^{2}$ and Gye-Chun Cho ${ }^{2}$ \\ ${ }^{1}$ Geotechnical Engineering Research Institute (GERI), Korea Institute of Civil Engineering and Building Technology (KICT), \\ Goyang 10223, Republic of Korea \\ ${ }^{2}$ Department of Civil and Environmental Engineering, Korea Advanced Institute of Science and Technology (KAIST), \\ Daejeon 34141, Republic of Korea
}

Correspondence should be addressed to Gye-Chun Cho; gyechun@kaist.edu

Received 5 August 2015; Revised 3 November 2015; Accepted 11 November 2015

Academic Editor: Shiv Shankar

Copyright (C) 2015 Ilhan Chang et al. This is an open access article distributed under the Creative Commons Attribution License, which permits unrestricted use, distribution, and reproduction in any medium, provided the original work is properly cited.

Earth buildings are still a common type of residence for one-third of the world's population. However, these buildings are not durable or resistant against earthquakes and floods, and this amplifies their potential harm to humans. Earthen construction without soil binders (e.g., cement) is known to result in poor strength and durability performance of earth buildings. Failure to use construction binders is related to the imbalance in binder prices in different countries. In particular, the price of cement in Africa, Middle East, and Southwest Asia countries is extremely high relative to the global trend of consumer goods and accounts for the limited usage of cement in those regions. Moreover, environmental concerns regarding cement usage have recently risen due to high $\mathrm{CO}_{2}$ emissions. Meanwhile, biopolymers have been introduced as an alternative binder for soil strengthening. Previous studies and feasibility attempts in this area show that the mechanical properties (i.e., compressive strength) of biopolymer mixed soil blocks (i.e, both 1\% xanthan gum and 1\% gellan gum) satisfied the international criteria for binders used in earthen structures. Economic and market analyses have demonstrated that the biopolymer binder has high potential as a self-sufficient local construction binder for earth buildings where the usage of ordinary cement is restricted.

\section{Introduction}

Earth has been the most commonly used material for building and construction since the beginning of human civilization. Since the Industrial Revolution, diverse building and construction materials such as cement and steel have become the basis of modern civilization and have replaced the use of conventional building materials (i.e., earth and wood). However, it was reported that about $30 \%$ of residential buildings were still made of earth as of 1994 (Figure 1) [1]. More specifically, the portion of residential buildings made of earth is close to $50 \%$ in developing countries as well as the third world. And in developed countries (USA, EU, etc.), demand for earth buildings has been increasing in accordance with increased interest in environment-friendly architecture and construction [1].
Earth house types can be categorized by the usage of construction binders (e.g., cement) and the main formation method [2-7]. However, as a building material, soil is limited in strength and durability. Damage to earthen buildings caused by intensive rainfall, floods, and earthquakes has been widely reported [8-10]. Nonetheless, people living in Southwest Asia, the Middle East, and Africa still rely on residential buildings made of soil. The use of binders is an important factor because it influences the strength of soil buildings, regardless of the type of wall formation.

Diverse types of binders made for construction have been used widely for soil buildings, but the production of binder also entails the generation of carbon dioxide. The production process for cement (which is the most universal binder for construction) has specifically been noted as the source of about $5 \%$ of global greenhouse gases $\left(\mathrm{CO}_{2}\right)$ and accordingly 
TABLE 1: Market price of cement ${ }^{1}$ in each country.

\begin{tabular}{|c|c|c|c|c|c|}
\hline Continents & Countries & Cement price (USD/ton) & Continents & Countries & Cement price (USD/ton) \\
\hline \multirow{9}{*}{ Africa } & Niger & 280 & \multirow{7}{*}{ Asia } & South Korea & 68 \\
\hline & Kenya & 190 & & China & 57 \\
\hline & Mali & 203 & & Japan & 125 \\
\hline & Mozambique & 160 & & India & 98 \\
\hline & Nigeria & 223 & & Pakistan & 106 \\
\hline & Cameroon & 200 & & Bangladesh & 112 \\
\hline & Rwanda & 200 & & Indonesia & 125 \\
\hline & Morocco & 150 & \multirow{2}{*}{ America } & Peru & 202 \\
\hline & Egypt & 65 & & United States & 91 \\
\hline \multirow{4}{*}{ Middle East } & Yemen & 214 & \multirow{4}{*}{ Europe } & Russia & 89 \\
\hline & Afghanistan & 91 & & Germany & 93 \\
\hline & Iraq & 120 & & France & 132 \\
\hline & Kuwait & 74 & & UK & 102 \\
\hline
\end{tabular}

${ }^{1}$ Source of the price of cement: global cement institute (www.globalcement.com).

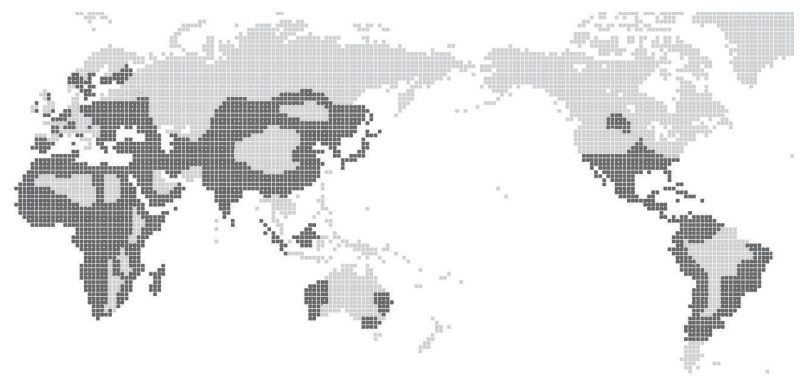

FIGURE 1: Global distribution of earth buildings [1].

the necessity of restraining the use of cement has been raised [11]. Moreover, the global cement price distribution shows regional differences (Table 1), and cement is especially expensive in underdeveloped countries. For instance, in China, the price of 1 ton of bulk cement was 57 USD/ton, while in Nigeria it was 223 USD/ton (about 4 times higher) [12].

Generally, the market price of consumer goods tends to increase along with an increase of GDP per capita [13]. But contrary to the general market trend, the price of cement appears asymmetrically high in countries with low GDP per capita while it appears low in countries of high GDP per capita (Figure 2). This is one factor likely facilitating the imbalance in the utilization of cement. The level of market demand for cement in developed countries is comparatively lower than that in less developed or developing countries because urbanization and social infrastructure have already been largely stabilized, whereas developing countries would be expected to have higher construction demands. Therefore, it is quite important to correct such disparities in the price of cement and other construction materials.

Biopolymers are normally composed of biodegradable polysaccharides and are generated by organisms such as algae, bacteria, and fungi by consuming carbon during cultivation. Diverse kinds of biopolymers have been discovered

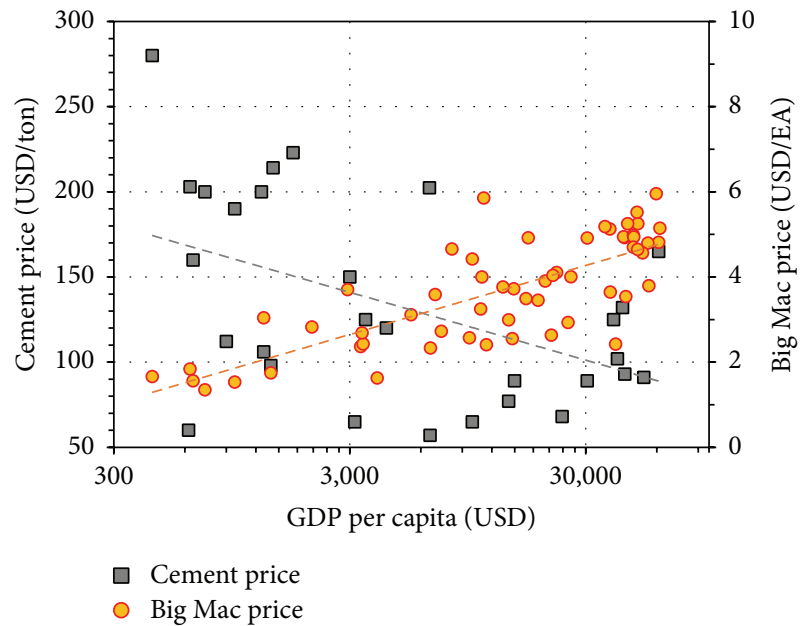

FIGURE 2: Global cement and Big Mac price trends with GDP per capita.

and developed in many fields for respective applications. In particular, with rising oil prices and the threat of increasing $\mathrm{CO}_{2}$ emissions, the market for biopolymer based plastic products has been expanding, as a replacement for high $\mathrm{CO}_{2}$ emitting products.

Several attempts to introduce biogenic biopolymers as an additive or supplement in construction engineering have been reported. Matsuoka et al. [14] performed a study using curdlan as a viscosity agent to improve the workability of concrete, while Chang and Cho $[15,16]$ showed that betaglucan treatment enhances the strength of natural soil with an increment ratio of up to $300-400 \%$ and also has low impact on the environment in terms of $\mathrm{CO}_{2}$ emissions. Moreover, the usage of gel type biopolymers (i.e., gellan gum and agar gum) was recently introduced in the field of soil treatment $[17,18]$. In this study, we performed experiments to evaluate the feasibility of gel type biopolymers (i.e., xanthan gum and 
gellan gum) as construction binders for earth buildings using natural soil.

\section{Materials and Methods}

\subsection{Biopolymers}

2.1.1. Xanthan Gum. Xanthan gum is an anionic polysaccharide composed of D-glucuronic acid, D-mannose, pyruvylated mannose, 6-O-acetyl D-mannose, and 1,4-linked glucan [19], produced by the fermentation of glucose or sucrose by Xanthomonas campestris bacterium [20]. Xanthan gum is commonly used as a food additive and rheology modifier. A recent study showed that xanthan gum improves the strength of soil significantly, especially in the presence of clayey particles (i.e., due to hydrogen bonding between xanthan gum and clay particles) [18]. The xanthan gum (SigmaAldrich, CAS number 11138-66-2) used in this study is from a biological source, Xanthomonas campestris.

2.1.2. Gellan Gum. Gellan gum is a water-soluble polysaccharide fermented from Sphingomonas elodea microbe and it consists of glucose, glucuronic acid $\left(\mathrm{C}_{5} \mathrm{H}_{9} \mathrm{O}_{5}-\mathrm{COOH}\right)$, and rhamnose $\left(\mathrm{C}_{6} \mathrm{H}_{12} \mathrm{O}_{5}\right)$. It forms a highly qualified gel even at low concentrations $(0.05-0.25 \%)$. Gellan gum is commonly used as a thickener, emulsifier, and stabilizer for food products [21]. Due to its high stability at high temperatures and low $\mathrm{pH}$ conditions, gellan gum is potentially a highly durable additive for soil improvement and stabilization [22, 23]. Gelzan (CP Kelco, CAS number: 71010-52-1), a commercial gellan gum product, was used in this study.

2.2. Materials: Korean Residual Soil (KRS), Hwangtoh. To investigate the soil strengthening effect of biopolymer treatment, we used Korean residual soil (KRS) as the soil material in this study. KRS is well known as "hwangtoh" on the Korean peninsula and has been used as a soil building material through much of Korean history. KRS consists of quartz (8.4\%), kaolinite (45.8\%), halloysite (22.7\%), illite (14.8), and goethite (8.3\%) as its main minerals, and detailed geotechnical properties of KRS can be found in Chang and Cho [15].

Like other adobe or soil buildings, KRS buildings have weaknesses in strength and durability. Thus, we tested the use of biopolymers as a mixing binder to reinforce the strength of natural KRS. Natural KRS from Gochang, Korea, was air-dried at room temperature $\left(18^{\circ} \mathrm{C}\right)$ and pulverized (i.e., detachment of agglomerated soil particles) to be suitable for proper mixing.

2.3. Sample Preparation and Strength Measurement. In the laboratory, we mixed KRS with xanthan gum and gellan gum to prepare biopolymer-treated KRS cube specimens. Ordinary Portland Cement (OPC) mixed and untreated (i.e., natural) KRS samples were prepared simultaneously, to compare the strengthening behavior of biopolymer treatment with preexisting soil construction (i.e., strengthening) methods.
For biopolymer (i.e., xanthan gum and gellan gum) mixing, $1000 \mathrm{~g}$ of dried and ground KRS was first mixed with $10 \mathrm{~g}$ (i.e., $m_{b} / m_{s}=1 \%$ ) of pure dried biopolymer powder (dry mixing stage), where $m_{b}$ and $m_{s}$ are the mass of the biopolymer and dry soil, respectively. Then, $600 \mathrm{~g}$ of distilled water (i.e., water content; $w=60 \%$ ) was added according to the liquid limit value (i.e., 53.7\%) of natural KRS [15] to provide thorough mixing to finally obtain uniform biopolymer-soil mixtures (wet mixing stage) (Figure 3(a)).

For OPC mixing, the cement to soil ratio in mass units $\left(m_{c} / m_{s}\right)$ was fixed at $10 \%$, based on results of previous studies, which show compressive strength of $m_{c} / m_{s}=10 \%$ cement treatment in accordance with $1.0 \%$ biopolymer content to soil mass (i.e., $m_{b} / m_{s}$ ) conditions $[15,18]$. Furthermore, $700 \mathrm{~g}$ of cement slurry with a water-cement ratio of 6 (i.e., $w / m_{c}=600 \mathrm{~g} / 100 \mathrm{~g}$ ) was prepared to obtain a cement-soil mixture with an identical initial water content condition that biopolymer-soil mixtures have (i.e., $w=60 \%$ ), when mixed with $1000 \mathrm{~g}$ of dry KRS.

The details of each mixing condition are summarized in Table 2. After mixing, the soil mixtures were poured into cubic molds $(50 \mathrm{~mm} \times 50 \mathrm{~mm} \times 50 \mathrm{~mm}$ ) (Figure 3(b)). Soils were compacted manually by a steel rod having a square head (i.e., $40 \mathrm{~mm} \times 40 \mathrm{~mm}$ ) and a rubber hammer to present optimal compaction and remove entrapped air voids from the soil mixtures. Cube samples were demolded and dried in air at room temperature $\left(18^{\circ} \mathrm{C}\right)$ for 28 days, followed by unconfined compressive strength measurement at the end of drying via a UTM (Universal Testing Machine; INSTRON 5583) device (Figure $3(\mathrm{~d})$ ) with a $1.0 \% / \mathrm{min}$ strain rate on three specimens to obtain average values, respectively [24]. All geometric dimensions were measured, as was the specimen mass, and top and bottom surfaces were slightly trimmed to avoid an uneven stress distribution during the testing. Additionally, in order to prevent stress localization, filter paper was placed above and below the samples during testing. Samples were loaded until failure and the residual compressive strength was observed.

\section{Results and Discussion}

3.1. Compressive Strength of Biopolymer-Soil Mixtures. In general, the compressive strength of soil-cement mixtures (i.e., $m_{c} / m_{s}=10 \%$ ) increases with dry density increment [25]. Figure 4 presents the compressive strength of xanthan gum, gellan gum, $10 \%$ cement, and untreated KRS mixtures after 28 days of dry curing (i.e., exposed to air) at room temperature (i.e., $20^{\circ} \mathrm{C}$ ). The strength values in Figure 4 are converted strength values that correspond to $100 \mathrm{~mm} \times$ $100 \mathrm{~mm} \times 100 \mathrm{~mm}$ cubes, by multiplying a shape factor value $\delta=0.85$ to the real compressive strength measurements for generalization (i.e., to avoid different shape and size effects) [26, 27].

Both $1 \%$ xanthan gum and $1 \%$ gellan gum treated soils show higher compressive strength values than the $10 \%$ cement mixed KRS. The strength of the soil mixed with $1 \%$ of xanthan gum was $6.31 \mathrm{MPa}$, which is more than 2.3 times higher than that of the soil mixed with $10 \%$ of Ordinary Portland Cement (i.e., 2.65 MPa). A previous study shows 


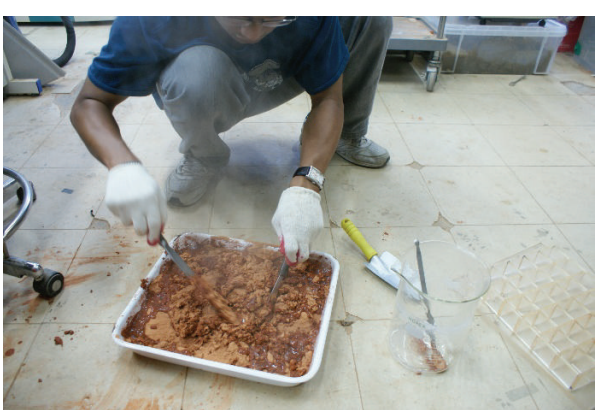

(a)

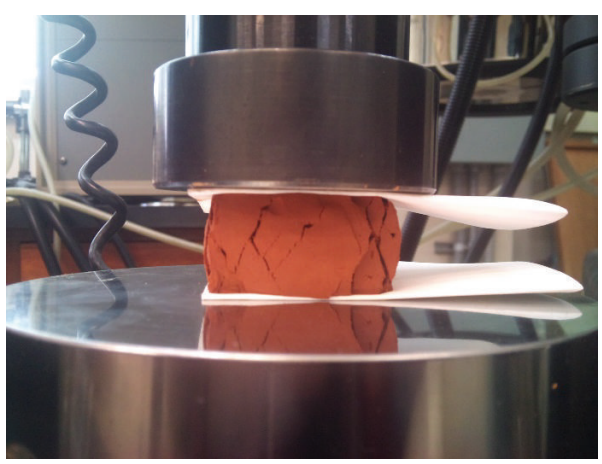

(c)

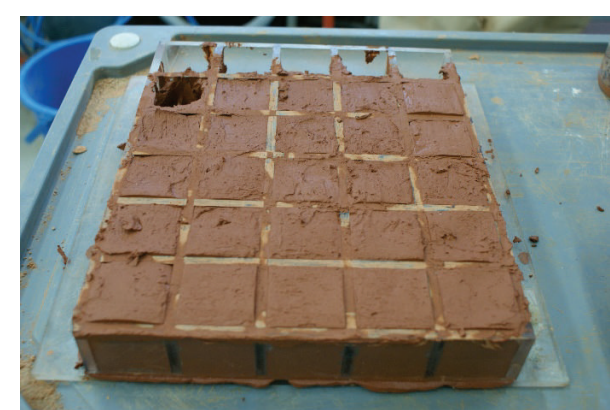

(b)

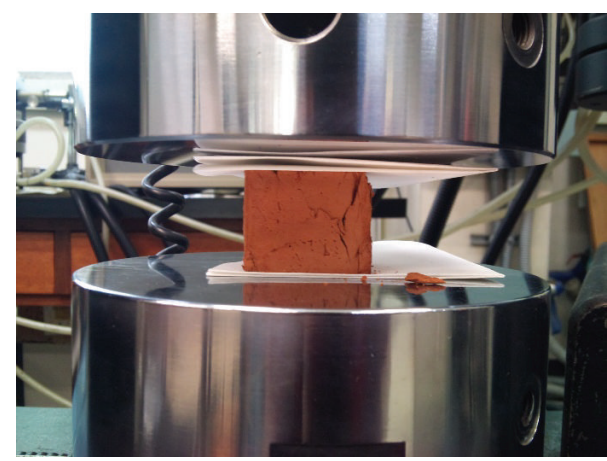

(d)

FIGURE 3: Experimental program. (a) Biopolymer-soil mixing. (b) Mixture molding. (c) UTM after 1 day of curing (ductile). (d) UTM at 28 days of curing (brittle and strong).

TABLE 2: Mixing conditions of biopolymer-KRS mixtures.

\begin{tabular}{|c|c|c|c|c|c|}
\hline \multirow{2}{*}{ Specimen } & \multicolumn{3}{|c|}{ Mixing condition $[\mathrm{g}]$} & \multicolumn{2}{|c|}{ Initial mass ratio [\%] } \\
\hline & Dried soil & Binder & Water & Binder/soil & Water content \\
\hline Xanthan gum & 1,000 & 10 & 600 & 1.0 & 60 \\
\hline Gellan gum & 1,000 & 10 & 600 & 1.0 & 60 \\
\hline Ordinary cement & 1,000 & 100 (cement) & 600 & 10.0 & 60 \\
\hline Natural (untreated) soil & 1,000 & - & 600 & - & 60 \\
\hline
\end{tabular}

that $0.5 \%$ of xanthan gum in the soil mixture could increase its strength above the level of soil mixed with $10 \%$ cement [18]. This means that either $100 \mathrm{~kg}$ of cement (10\% of the soil) or $5 \mathrm{~kg}$ of xanthan gum $(0.5 \%$ of the soil) would be needed to make 1 ton of soil having a strength over $2.5 \mathrm{MPa}$.

In the initial mixing stage, biopolymers tend to adsorb water immediately and form hydrogels, which enlarge the pore space between soil particles at molding. During curing and dehydration, water evaporates from the hydrogels, rendering firmer and stronger matrices between the biopolymers and soil particles. As a result, the final dried biopolymer-soil mixture can have high strength even under relatively low dry density (i.e., $1 \%$ gellan gum $=1.35 \mathrm{~g} / \mathrm{cm}^{3}, 1 \%$ xanthan gum $=$ $1.38 \mathrm{~g} / \mathrm{cm}^{3}$, and $10 \% \mathrm{OPC}=1.44 \mathrm{~g} / \mathrm{cm}^{3}$ in this study).

Several design criteria are set for bricks used for construction and building engineering (Table 3 ). The most common brick type in construction engineering is the cement-based brick. The Eurocode (EN 1996-3) requires a masonry cementsand brick unit $(100 \mathrm{~mm} \times 100 \mathrm{~mm} \times 100 \mathrm{~mm}$ cube $)$ to have a compressive strength of at least $2 \mathrm{MPa}$ for a $10 \%$ cement
TABLE 3: Design criteria for earthen structures.

\begin{tabular}{|c|c|c|c|}
\hline Design criteria & BS EN 1996-3 ${ }^{1}$ & BS EN $771-1^{2}$ & IBC $2012^{3}$ \\
\hline $\begin{array}{l}\text { Minimum } \\
\text { compressive } \\
\text { strength [MPa] }\end{array}$ & $\begin{array}{c}2 \mathrm{MPa} \text { (for } 10 \% \\
\text { cement : soil) } \\
6 \mathrm{MPa} \text { (for } 20 \% \\
\text { cement : soil) }\end{array}$ & $\begin{array}{c}5 \mathrm{MPa} \text { (soil } \\
\text { brick) }\end{array}$ & $\begin{array}{c}2 \mathrm{MPa} \\
\text { (rammed } \\
\text { earth brick) }\end{array}$ \\
\hline
\end{tabular}

${ }^{1}$ Eurocode 6: design of masonry structures (standard compressive strength for $100 \mathrm{~mm} \times 100 \mathrm{~mm} \times 100 \mathrm{~mm}$ cube).

${ }^{2}$ Specification for compacted clay masonry units (compressive strength of $337.5 \mathrm{~mm} \times 112.5 \mathrm{~mm} \times 112.5 \mathrm{~mm}$ brick).

${ }^{3}$ International Building Code (IBC), International Code Council (ICC) 2012.

to sand ratio and $6 \mathrm{MPa}$ for a $20 \%$ cement to sand ratio [28]. Another British code (BS EN 771-1) defines the minimum compressive strength for $337.5 \mathrm{~mm}$ (width) $\times 112.5 \mathrm{~mm}$ (length) $\times 112.5 \mathrm{~mm}$ (height) soil bricks to be $5 \mathrm{MPa}$ [29], which is identical to a standard compressive strength value of $4.6 \mathrm{MPa}$ by applying a shape factor value $\delta=0.92$ [26]. Meanwhile, the International Code Council (ICC) provides 


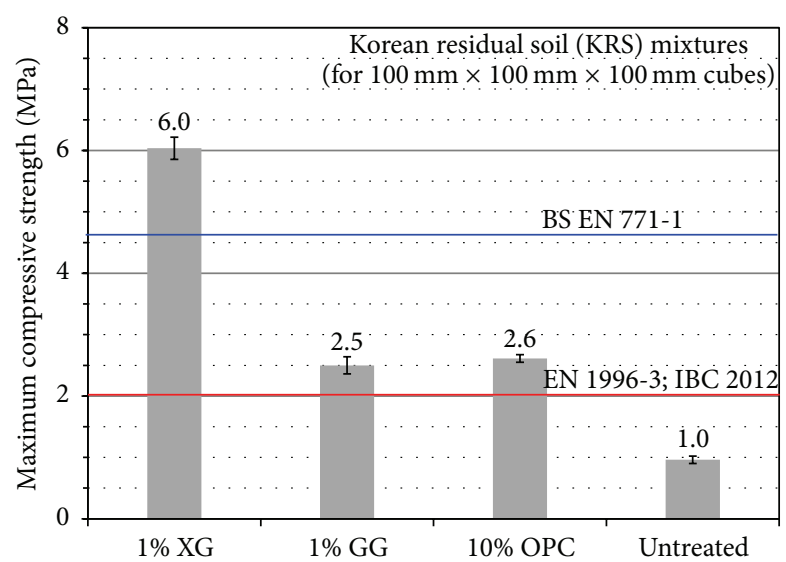

FIGURE 4: Maximum compressive strength values of KRS specimens and design criteria for earthen structures.

detailed requirements for earth walls, where the compressive strength of a rammed earth brick should exceed $2 \mathrm{MPa}$ for a converted specimen scale (i.e., $100 \mathrm{~mm} \times 100 \mathrm{~mm} \times 100 \mathrm{~mm}$ ) [30].

The average maximum compressive strength values of KRS specimens at 28 days are compared with typical design criteria of masonry structures (i.e., EN 1996-3, BS EN 771-1, and IBC 2012) in Figure 4. Untreated KRS has an unconfined compressive strength value close to $1 \mathrm{MPa}$, while $1 \%$ xanthan gum treatment produces the highest strengthening effect. The strength of $10 \%$ OPC mixed KRS (i.e., 2.65 MPa) satisfies the minimum strength criteria to be a brick. The compressive strengths of both xanthan gum (i.e., 6.3 MPa $>2 \mathrm{MPa}$ ) and gellan gum (i.e., $2.50 \mathrm{MPa}>2 \mathrm{MPa}$ ) mixes are in accordance with strength values in previous studies $[17,18]$ and satisfy the strength criteria to be used as a rammed earth brick binder [30].

Meanwhile, BS EN 1996-3 establishes the minimum strength of a wall element for a low-rise building to be higher than 5.2 MPa. In this aspect, 10\% cement mixed KRS and 1\% gellan gum mixed KRS are insufficient for use for single-story buildings, while $1 \%$ xanthan gum mixing is applicable for lowrise soil building construction. Moreover, the high strength of $1 \%$ xanthan gum treatment (i.e., 6.3 MPa) is a compressive strength level almost equivalent to the minimum strength of $20 \%$ ordinary cement mixing (i.e., $6 \mathrm{MPa}$ ), indicating the high strengthening efficiency of xanthan gum treatment, even with $1 / 20$ th (i.e., $1 \%$ versus $20 \%$ ) the amount of material quantity compared to cement mixing.

Given the mechanical performance of biopolymer treatment, biopolymers are highly feasible for use as soil binders. However, the strength and stability of soil structures become critical with the presence of excess water conditions (e.g., wet or submerged). A previous study shows that the wet strength of biopolymer-treated soils is reduced to approximately $1 / 10$ th that of the dry strength when fully saturated under water [17]. Thus, water resistance or wet strength improvement methods of biopolymer-treated soils must be considered in further studies. Moreover, the economic feasibility of biopolymer application as a soil binder must be clearly demonstrated to declare biopolymers a promising construction and building material in the near future.

3.2. Future Prospects of Biopolymers as an EnvironmentFriendly Building Material. Petrochemical polymers have been applied diversely in modern civilization due to their demonstrated excellent performance. However, their prices are sensitive to fluctuations in oil prices, and they come with the added disadvantages of environmental damage, due to their retarded degradability, and the creation of carbon dioxide in their production process. Consequently, the need for more environment-friendly polymers has emerged, and accordingly studies to develop diverse bio-based plastics or polymers have been actively conducted [31].

Bio-based plastics or polymers can have diverse molecular structures depending on their respective polymerization processes, and this has enabled the production of customized biopolymers that have desirable strength or plasticity, with inherent biodegradability, along with low or limited carbon dioxide generation during production. On this basis, they have been regarded as a promising alternative to petrochemical products [32]. Research and market development of such products have been primarily based in regions that have strict regulations related to environment preservation, such as Japan and Europe, and the European biopolymer market currently accounts for about $60 \%$ of the entire global market.

Major global companies in the areas of chemical engineering and product manufacture are leading the development and production of biopolymers and bioplastics. Recently, several leading companies concluded an agreement together to produce environment-friendly biopolymers, and they introduced specifications and a certification system for biodegradable polymers [33]. They currently provide consumers with information about their certified products [34]. That agreement and the mutual cooperation of these corporations have brought about increased demand and improved reliability for bio-based polymer products. Biopolymers are currently applied in diverse fields including medicine, foods, cosmetics, and agrichemicals, and their markets have been growing by over $23 \%$ annually since 2010 . This market growth trend is expected to continue for the time being $[35,36]$.

3.3. Economic Feasibility and Future Prospects for BiopolymerSoil Treatment. The economic feasibility of biopolymers has been growing due to the expansion of biopolymer markets and the development of technologies associated with biopolymers (Figure 5). From 2009 to 2011, the global market for bioplastics increased from 249,000 tons to $1,161,000$ tons annually (4.6 times), with a resulting price decrease [37-39].

The price competitiveness of biopolymers, which were 35-100 times more expensive in the early 2000s relative to conventional petrochemical polymers, has also been improving. The price gap had dropped by $2.5-7.5$ times in 2007 by virtue of consistent development in technology and increased environmental regulations [39]. For instance, the price of xanthan gum in the 1960s was about 30,000 USD/ton, while it had dropped to $1 / 4$ that amount by 2014 (Figure 6), due to expanded applications (e.g., medicine, cosmetics, construction, etc.) and subsequent technological development. 


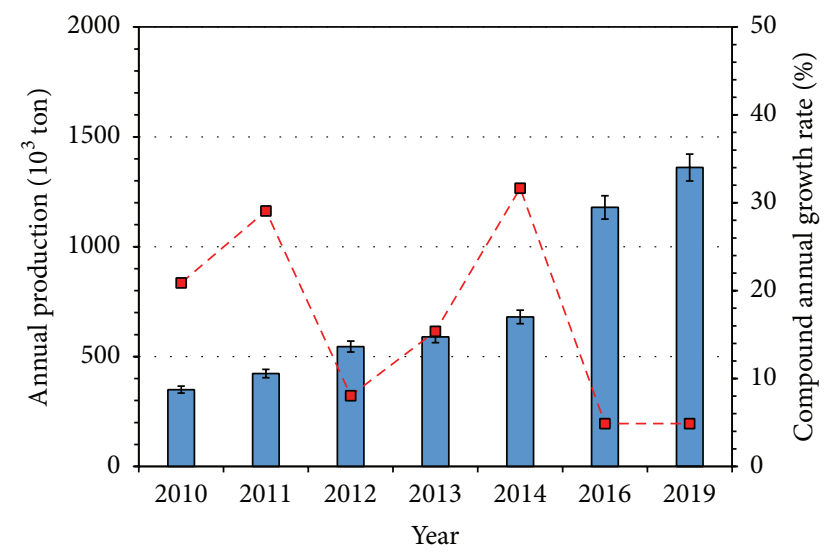

Global market of biopolymers

$\square$ Annual production

- - Compound annual growth rate (CAGR)

FIGURE 5: Expected trend and growth of the global biopolymer market.

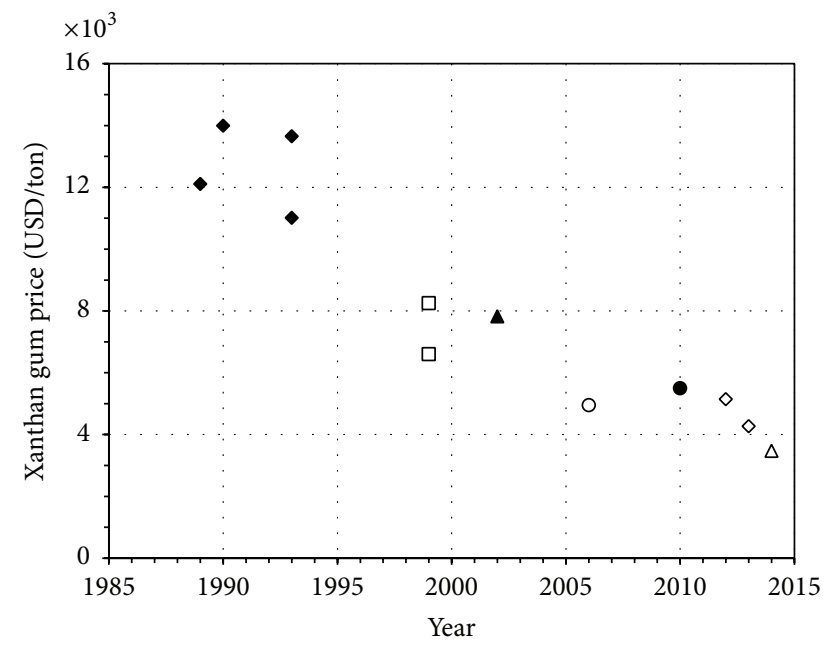

- USDA (1993)

$\square$ Industrial market research (1999)

\ Chemical market reporter (2002)

O ICIS news (2006)

- Industrial market research (2013)

$\diamond$ China chemicals market (2013)

$\triangle$ Research and markets (2014)

Figure 6: Market price trend of xanthan gum over 30 years (19852014).

In general, the major factors determining the price level of biopolymers such as xanthan gum are (1) the source of carbon, (2) the fermentation process, and (3) the recovery ratio. In particular, the level of biopolymer recovery from the fermentation medium (i.e., carbon source, e.g., sugar water and glucose) is an essential component affecting cost.

Regarding the importance of improving the recovery ratio, it was reported that a $20 \%$ increase in the recovery of biopolymers (from $60 \%$ to $80 \%$ ) could reduce the price of the

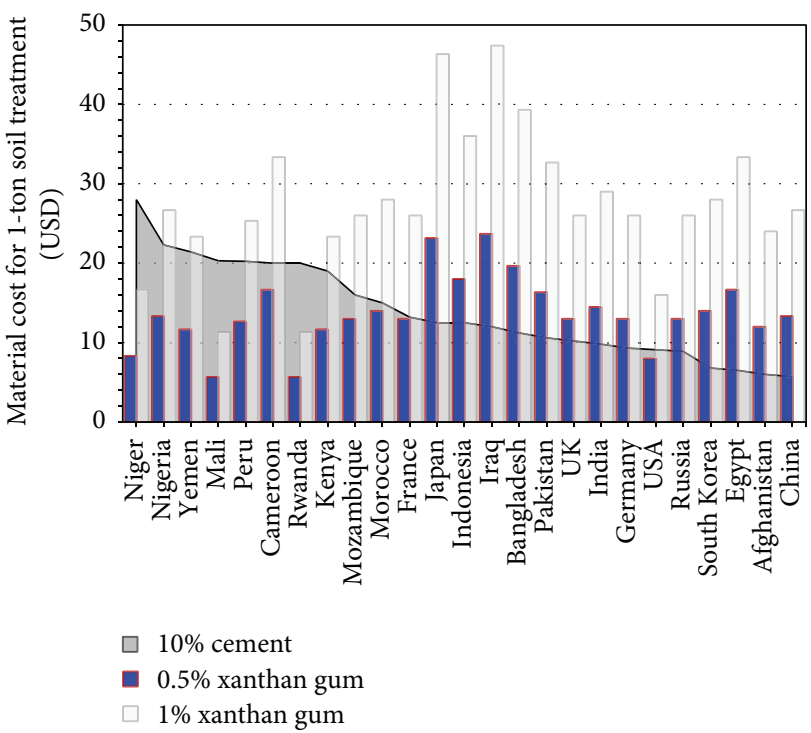

FIGURE 7: Estimated cost comparison for 1-ton soil treatment using cement $(10 \%)$ and XG (0.5\% and $1 \%)$.

biopolymer by $10 \%$ [40]. Many studies investigating methods to improve the recovery of biopolymers have focused on changing process conditions such as $\mathrm{pH}$, temperature, agitation rate, nitrogen source concentration, and phosphor source concentration [41]. Consequently, biopolymer production technology has been continuously improved and the recovery ratio, which remained at a level of $30 \%$ in the 1970 s, has now reached $60 \%$ in the commercial production process [42].

In addition, there have been many efforts to diversify the biopolymer carbon source, which is the major constituent of the macromolecular polysaccharide, as well as studies aimed at optimizing the production conditions of biopolymers [4345]. The carbon source plays an important role in biopolymer commercialization because it accounts for approximately $30 \%$ of the whole production cost of biopolymers [41, 46]. Therefore, securing a sustainable and consistent carbon source is important for establishing a stable market for biopolymers.

For instance, the price of starch varies from 240 to $500 \mathrm{USD} /$ ton, with a global average of $390 \mathrm{USD} /$ ton in 2014 [47], reflecting much greater stability than the severe intercontinental differences in the global cement market (Table 1 and Figure 2). Thus, it becomes possible to perform cost comparisons between cement treatment and biopolymer (i.e., xanthan gum) treatment for soil strengthening by considering the cost ratio between produced xanthan gum and its carbon source (i.e., starch) [41, 46], as shown in Figure 7.

Figure 7 implies that xanthan gum treatment as a soil binder is already more competitive than cement in African countries. For instance, the price of starch in Kenya is reported to be $350 \mathrm{USD} /$ ton [47]. Thus, the cost of locally produced xanthan gum can be estimated to become $2,333 \mathrm{USD} /$ ton [i.e., $350 \mathrm{USD} /$ ton (starch price) $\div 0.5$ (recovery ratio) $\div 0.3$ (proportion in total cost) $=2,333$ USD/ton], 
which indicates that the xanthan gum cost for $0.5 \%$ soil treatment (i.e., $5 \mathrm{~kg}$ of xanthan gum for 1 ton of soil) is 11.7 USD. Therefore, application of xanthan gum in countries with high cement prices potentially would be more economical and effective in terms of $\mathrm{CO}_{2}$ emission reduction than cement usage, if xanthan gum is utilized for construction purposes and is locally produced. This could be accomplished by introducing an integrated commercialization process consisting of simple cultivation facility + local carbon source + germ/bacterium.

Moreover, most biopolymers sold in the current global market are food-grade, and up to 50\% of the production costs of food-grade biopolymers are related to downstream purification steps, many of which would not be necessary for nonfood applications such as construction [41, 48]. Thus the price of biopolymers produced for engineering or construction purposes is expected to be lower than prices for the current commercial biopolymers estimated earlier (i.e., by $50 \%$ or so). Also, further cost reduction could be achieved by using less expensive substrates, such as agricultural product waste.

\section{Conclusions}

About $30 \%-40 \%$ of the world's population are still dwelling in buildings made of soil despite massive urbanization using modern construction technology. Such a high portion of the population is dwelling in soil buildings due to interrelated economic and environmental factors, including the availability of soil as a local and inexpensive construction material. This is problematic, since traditional soil buildings (made of soils without binders) are typically vulnerable to water and seismic loads. To cope with such problems, binders are required for soil strengthening. However, the most representative construction binder for soils (i.e., cement) accounts for more than $5 \%$ of the global annual $\mathrm{CO}_{2}$ emissions [49-51], which becomes a concern when formulating scientific policy. In addition, the price of cement varies widely by country. In particular, it was determined that the price of cement in countries with lower GDP per capita was significantly higher than the average price in the global market. It is interesting that the countries with low GDP per capita are the most highly dependent on soil buildings, and it appears that this dependence on soil buildings is due to the very high price of construction binders, especially cement.

Thus, in this study, the use of microbially produced biopolymers as an economic and environment-friendly alternative binder for the construction of soil buildings is introduced. Feasibility studies conducted to test the comparative strength of soils treated with biopolymers confirmed that a very small amount (i.e., $0.5 \%$ of the whole contents) of biopolymers mixed with soil resulted in a higher unconfined compression strength than that of soil mixed with a large amount of cement (i.e., $10 \%$ of the whole content).

The economic feasibility of biopolymers relative to cement has yet to be improved; however with the trend of technological developments in this field it is highly likely that a market of biopolymers for construction purposes will develop. Further cost reductions are expected with the improved recovery ratio of biopolymers, together with the diversification and exploration of low priced carbon sources, and the commercialization and mass production of biopolymers specifically for construction purposes. These advances will enable countries with higher cement prices to obtain comparatively cheaper local construction binders. Furthermore, since the prices of carbon sources primarily used for the cultivation of biopolymers are lower in less developed countries, where the cost of cement is highest, the local commercialization of such biopolymers could contribute to the improvement of the strength and durability of soil buildings in countries that rely on them the most.

\section{Conflict of Interests}

The authors declare that there is no conflict of interests regarding the publication of this paper.

\section{Acknowledgments}

The research described in this paper was financially supported by a National Research Foundation of Korea (NRF) grant funded by the Korean government (MSIP) (no. 2015R1A2A2A03006268), by a grant from the Strategic Research Project (Development of Key Excavation Solutions for Expandable Urban Underground Space) funded by the Korea Institute of Civil Engineering and Building Technology (KICT), and by the KAIST End-Run Program (no. N01150661) supported by the Korea Ministry of Science, ICT and Future Planning (MISP).

\section{References}

[1] H. Houben and H. Guillaud, Earth Construction: A Comprehensive Guide, Intermediate Technology Publications, 1994.

[2] J. D. Revuelta-Acosta, A. García-Díaz, G. M. Soto-Zarazúa, and E. Rico-García, "Adobe as a sustainable material: a thermal performance," Journal of Applied Sciences, vol. 10, no. 19, pp. 22112216, 2010.

[3] P. J. Walker, "Strength and erosion characteristics of earth blocks and earth block masonry," Journal of Materials in Civil Engineering, vol. 16, no. 5, pp. 497-506, 2004.

[4] I. Evans, L. Smiley, M. G. Smith, and M. Smith, The HandSculpted House: A Philosophical and Practical Guide to Building a Cob Cottage, Chelsea Green Publishing Company, White River Junction, Vt, USA, 2002.

[5] S. T. Maqsood and J. Schwarz, "Analysis of building damage during the 8 October 2005 earthquake in Pakistan," Seismological Research Letters, vol. 79, no. 2, pp. 163-177, 2008.

[6] D. Easton, The Rammed Earth House, Chelsea Green Publishing Company, White River Junction, Vt, USA, 2007.

[7] D. Sadek and H. Roslan, "A review on bricks and stabilized compressed earth blocks," Scientific Research and Essays, vol. 6, no. 3, pp. 499-506, 2011.

[8] R. Coffman, N. Agnew, G. S. Austin, and E. Doehe, "Adobe mineralogy," in Proceedings of the 6th International Conference on the Conservation of Earthen Architecture, pp. 424-429, Las Cruces, NM, USA, October 1990.

[9] R. Meli, O. Hernandez, and M. Padilla, "Strengthening of adobe houses for seismic actions," in Proceedings of the 7th World 
Conference on Earthquake Engineering, pp. 465-472, Istanbul, Turkey, September 1980.

[10] M. R. Maheri, F. Naeim, and M. Mehrain, "Performance of adobe residential buildings in the 2003 Bam, Iran, earthquake," Earthquake Spectra, vol. 21, supplement 1, pp. S337-S344, 2005.

[11] C. A. Hendriks, E. Worrell, D. De Jager, K. Blok, and P. Riemer, "Emission reduction of greenhouse gases from the cement industry," in Proceedings of the 4th International Conference on Greenhouse Gas Control Technologies, pp. 939-944, 1998.

[12] International Cement Review, "Global cement report," Tech. Rep., International Cement Review, 2013.

[13] L. L. Ong, "Burgernomics: the economics of the Big Mac standard," Journal of International Money and Finance, vol. 16, no. 6, pp. 865-878, 1997.

[14] Y. Matsuoka, T. Shindoh, K. Yakota, and S. Kusui, "Property of $\beta$-1, 3-glucan (curdlan) as a viscosity agent for super-workable concrete," ACI Special Publication, vol. 173, pp. 475-491, 1997.

[15] I. Chang and G.-C. Cho, "Strengthening of Korean residual soil with $\beta$-1,3/1,6-glucan biopolymer," Construction and Building Materials, vol. 30, pp. 30-35, 2012.

[16] I. Chang and G.-C. Cho, "Geotechnical behavior of a beta1,3/1,6-glucan biopolymer-treated residual soil," Geomechanics and Engineering, vol. 7, no. 6, pp. 633-647, 2014.

[17] I. Chang, A. K. Prasidhi, J. Im, and G.-C. Cho, "Soil strengthening using thermo-gelation biopolymers," Construction and Building Materials, vol. 77, pp. 430-438, 2015.

[18] I. Chang, J. Im, A. K. Prasidhi, and G.-C. Cho, "Effects of Xanthan gum biopolymer on soil strengthening," Construction and Building Materials, vol. 74, pp. 65-72, 2015.

[19] M. C. Cadmus, L. K. Jackson, and K. A. Burton, "Biodegradation of xanthan gum by Bacillus sp.," Applied and Environmental Microbiology, vol. 44, no. 1, pp. 5-11, 1982.

[20] A. Becker, F. Katzen, A. Pühler, and L. Ielpi, "Xanthan gum biosynthesis and application: a biochemical/genetic perspective," Applied Microbiology and Biotechnology, vol. 50, no. 2, pp. 145-152, 1998.

[21] P.-E. Jansson, B. Lindberg, and P. A. Sandford, "Structural studies of gellan gum, an extracellular polysaccharide elaborated by Pseudomonas elodea," Carbohydrate Research, vol. 124, no. 1, pp. 135-139, 1983.

[22] I. Giavasis, L. M. Harvey, and B. McNeil, “Gellan gum," Critical Reviews in Biotechnology, vol. 20, no. 3, pp. 177-211, 2000.

[23] G. G. Ferruzzi, N. Pan, and W. H. Casey, "Mechanical properties of gellan and polyacrylamide gels with implications for soil stabilization," Soil Science, vol. 165, no. 10, pp. 778-792, 2000.

[24] ASTM D1633-00, Standard Test Methods for Compressive Strength of Molded Soil-Cement Cylinders, ASTM International, West Conshohocken, Pa, USA, 2007.

[25] P. J. Walker, "Strength, durability and shrinkage characteristics of cement stabilised soil blocks," Cement and Concrete Composites, vol. 17, no. 4, pp. 301-310, 1995.

[26] J. R. del Viso, J. R. Carmona, and G. Ruiz, "Shape and size effects on the compressive strength of high-strength concrete," Cement and Concrete Research, vol. 38, no. 3, pp. 386-395, 2008.

[27] M. Tokyay and M. Özdemir, "Specimen shape and size effect on the compressive strength of higher strength concrete," Cement and Concrete Research, vol. 27, no. 8, pp. 1281-1289, 1997.

[28] British Standard Institute, "Eurocode 6. Design of masonry structures. Simplified calculation methods for unreinforced masonry structures," BS EN 1996-3:2006, British Standard Institute, 2006.
[29] British Standard Institute, "Specification for masonry units. Clay masonry units," BS EN 771-1:2011, British Standard Institute, 2011.

[30] International Code Council, International Building Code 2012, International Code Council, 2011.

[31] G. Davis and J. H. Song, "Biodegradable packaging based on raw materials from crops and their impact on waste management," Industrial Crops and Products, vol. 23, no. 2, pp. 147-161, 2006.

[32] G. Scott, "Green polymers," Polymer Degradation and Stability, vol. 68, no. 1, pp. 1-7, 2000.

[33] European Standard, "Packaging-requirements for packaging recoverable through composting and biodegradation-test scheme and evaluation criteria for the final acceptance of packaging," CSN EN 13432, 2013.

[34] P. Helby, "Environmental agreements at European Community level-reflections based on member state experience," Journal of Cleaner Production, vol. 10, no. 2, pp. 183-193, 2002.

[35] GBI Research, Biopolymer Market Forecasts and Growth Trends to 2015-Starch-Based Polymers Driving the Growth, 2010.

[36] D. K. Platt and Rapra Technology Limited, Biodegradable Polymers: Market Report, Rapra Technology, Shrewsbury, UK, 2006.

[37] J. Lampinen, “Trends in bioplastics and biocomposites," Developments in Adcanced Biocomposites, VTT Technical Research Centre of Finland, Espoo, Finland, 2010.

[38] R. P. Babu, K. O’Connor, and R. Seeram, “Current progress on bio-based polymers and their future trends," Progress in Biomaterials, vol. 2, no. 1, pp. 1-16, 2013.

[39] Frost \&Sullivan, Global Bio-Based Plastics Market, Frost \&Sullivan Research Service, 2009.

[40] W. P. Weisrock, "Method for improving xanthan yield," Google Patents, 1981.

[41] F. García-Ochoa, V. E. Santos, J. A. Casas, and E. Gómez, "Xanthan gum: production, recovery, and properties," Biotechnology Advances, vol. 18, no. 7, pp. 549-579, 2000.

[42] A. Palaniraj and V. Jayaraman, "Production, recovery and applications of xanthan gum by Xanthomonas campestris," Journal of Food Engineering, vol. 106, no. 1, pp. 1-12, 2011.

[43] S. Kalogiannis, G. Iakovidou, M. Liakopoulou-Kyriakides, D. A. Kyriakidis, and G. N. Skaracis, "Optimization of xanthan gum production by Xanthomonas campestris grown in molasses," Process Biochemistry, vol. 39, no. 2, pp. 249-256, 2003.

[44] Q. Li, W. Yan, K. Yang, Y. Wen, and J.-l. Tang, "Xanthan gum production by Xanthomonas campestris pv. campestris 8004 using cassava starch as carbon source," African Journal of Biotechnology, vol. 11, no. 73, pp. 13809-13813, 2012.

[45] S. Moshaf, Z. Hamidi-Esfahani, and M. H. Azizi, "Optimization of conditions for xanthan gum production from waste date in submerged fermantation," World Academy of Science, Engineering and Technology, vol. 57, pp. 521-524, 2011.

[46] S. Rosalam and R. England, "Review of xanthan gum production from unmodified starches by Xanthomonas comprestris sp.," Enzyme and Microbial Technology, vol. 39, no. 2, pp. 197-207, 2006.

[47] Global Industry Analysts, Global Starch Industry, Global Industry Analysts, 2014.

[48] I. B. Bajaj, S. A. Survase, P. S. Saudagar, and R. S. Singhal, "Gellan gum: fermentative production, downstream processing and applications," Food Technology and Biotechnology, vol. 45, no. 4, pp. 341-354, 2007. 
[49] R. Rapier, "Global carbon dioxide emissions-facts and figures," Consumer Energy Report, 2012.

[50] R. Rehan and M. Nehdi, "Carbon dioxide emissions and climate change: policy implications for the cement industry," Environmental Science and Policy, vol. 8, no. 2, pp. 105-114, 2005.

[51] E. Worrell, L. Price, N. Martin, C. Hendriks, and L. O. Meida, "Carbon dioxide emissions from the global cement industry," Annual Review of Energy and the Environment, vol. 26, pp. 303329,2001 

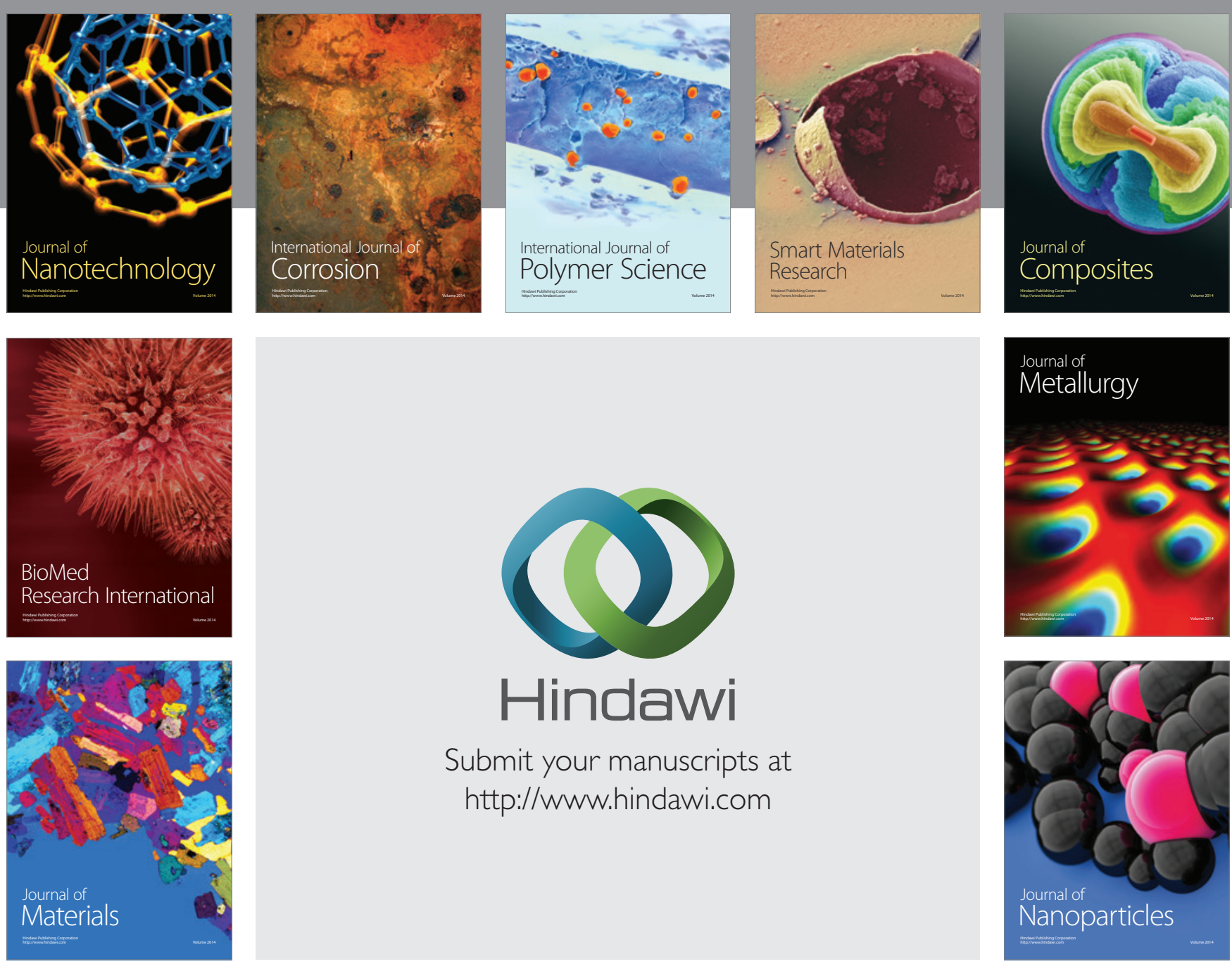

Submit your manuscripts at http://www.hindawi.com
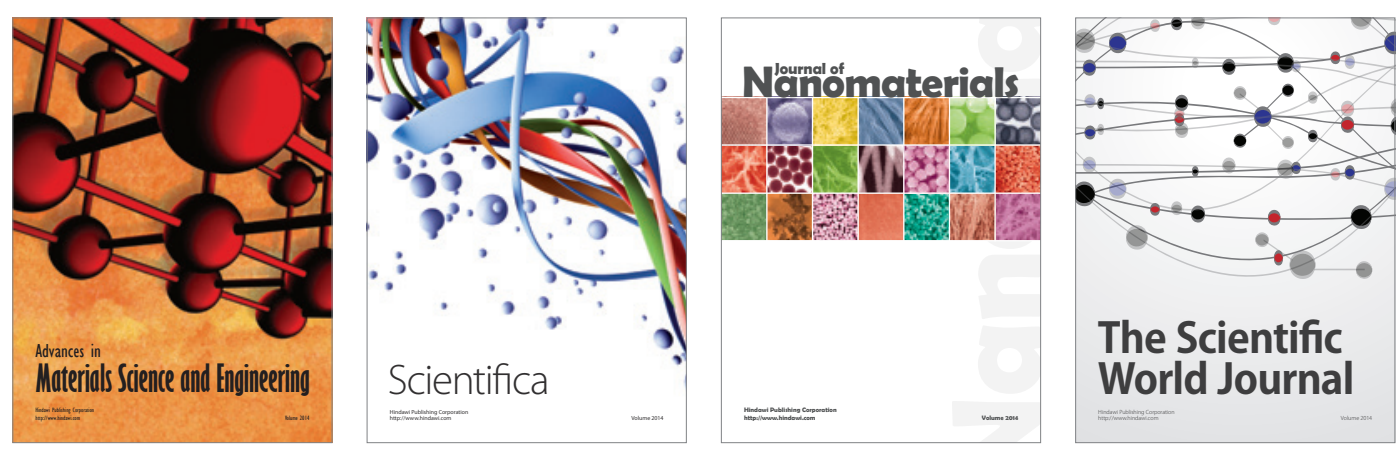

\section{The Scientific World Journal}
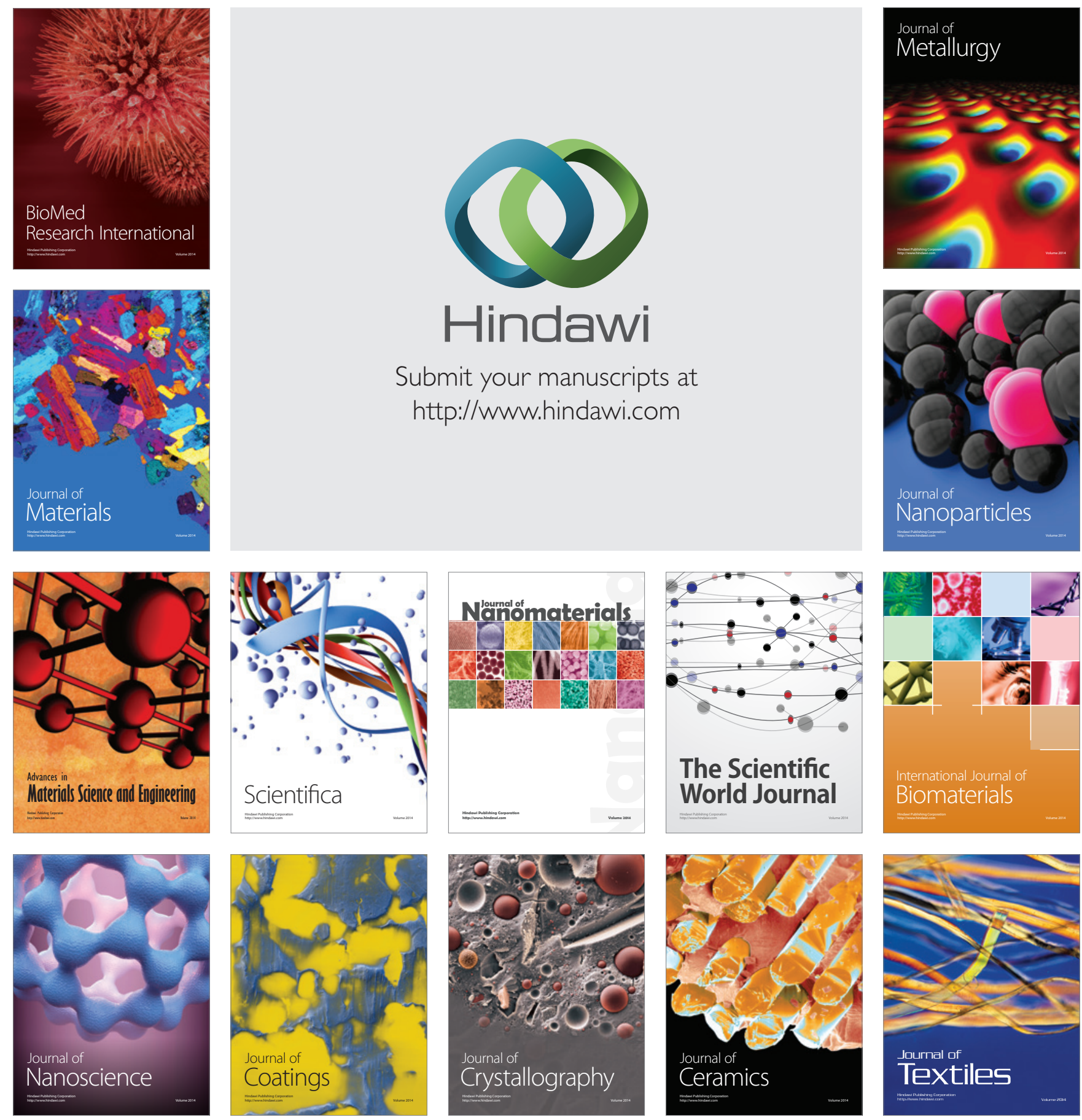